\title{
A MULHER VISTA PELOS DIREITOS SOCIAIS NA LEGISLACฺÃO INFRACONSTITUCIONAL BRASILEIRA PÓS CONSTITUIC̣ÃO DE 1988
}

\author{
Venicius Meneses Moreira ${ }^{1}$ \\ Pablo Regis Andrade ${ }^{2}$
}

RESUMO: Este artigo visa construir, de maneira analítica, uma caracterização generalizada da mulher como sujeito de direito, levantando seu papel social no que tange à onerosidade e direitos, à luz da legislação inerente a direitos sociais do Brasil pós Constituição Federal de 1988. Com fulcro no levantamento da Comissão Nacional da Mulher Advogada, mediante prerrogativas suscitadas no movimento feminista, procura-se problematizar uma figura chamada mulher. Atenta-se ao debate de gênero, além da diferenciação da ideia de gênero e sexo, bem como a dialética de dominação, poderes e interseccionalidade.

PALAVRAS-CHAVE: Constituição. Direito. Gênero. Leis. Mulher.

\section{ASPECTOS INICIAIS E O SUJEITO DE DIREITO}

Este estudo tem como contexto a frequente discussão relacionada a gênero, porém situada no legislativo nacional pós Constituição Federal de 1988, cujos conteúdos em análise são as produções legais que citam o termo mulher ou fazem alusão ao mesmo, de modo a problematizar quem é a mulher na escrita do direito.

À guisa, aborda-se no construto social legal brasileiro a personagem mulher num recorte dos "Direitos Sociais", o qual é uma referência legislativa, embora a igualdade de gênero não tenha sido alcançada de maneira plena em todas as designações do direito, argumenta Alves (2016).

O tema e as legislações encontram-se no sítio eletrônico da Comissão Nacional da Mulher Advogada (CNMA), entidade integrada ao Conselho Federal da Ordem dos Advogados do Brasil com uma discussão relevante à mulher, cujo papel é também verificar as Comissões da Mulher nas Seccionais promovendo debates no tocante aos direitos femininos e, como afirma Marques (2004), tal comissão assume a lutar por uma visibilidade das mulheres advogadas dentro da Ordem dos Advogados do Brasil (OAB), uma entidade considerada tradicionalmente masculina.

$\mathrm{Na}$ escrita dos termos de gênero, a igualdade segue com pacificidade, agregando ao homem e à mulher as mesmas obrigações e deveres quanto aos filhos. Outrossim, a igualdade e a dignidade da pessoa humana encontram-se expressos nos textos legais de modo a coibir injustiças por cor, raça e gênero.

1 Instituição: Faculdade Católica do Tocantins, Orcid: https://orcid.org/0000-0001-5536-5814 , E-mail: veniciusmm@gmail.com 2 Instituição: Faculdade Católica do Tocantins, Orcid: https://orcid.org/0000-0001-5671-3120, E-mail: pablo.andrade@catolica-to.edu.br 
Considerando a instituição de relevantes direitos acerca da igualdade de gênero na sociedade e no meio conjugal a partir da reconhecida constituição cidadã (1988), trazemos para a discussão sobre o termo "mulher" uma hipótese macrossocial ainda vigente no Brasil quanto à permanência ideológica de submissão desta pessoa, numa filiação lógica de dominação ainda que importantes lutas do movimento feminista por igualdade tenham sido observadas no século XIX, cujas discussões são feitas por Beauvoir (2002).

Em princípio, assumimos o gênero enquanto um padrão formatado, objetivado, que indica comportamentos dados, sob o qual as escolhas são irrelevantes mediante uma subjetividade extrinsecamente impositiva. Conforme já apontava Friedman (1971), a mulher, personagem central deste estudo, fora idealizada e objetificada tanto em seu valor quanto no compromisso de uma feminilidade, ambos advindos de fontes externas a si mesma. A palavra "mulher" confunde-se com o papel doméstico a ela atribuído, fixado ainda à reprodução humana, às decisões emocionais e irracionais, enquanto que ao termo "homem" a representação é de um ser público, viril, sendo tal indivíduo o que atua por relações lógicas e de produtividade (BEAUVOIR, 2002). Dá-se aqui um relevante endosso desta pesquisa que trata da problemática relação social sobre a mulher no interpretativo da legislação infraconstitucional quando este termo é registrado, atribuindo-lhe então uma forma.

No âmbito legal, a presente discussão evoca uma compreensão do conceito basilar de "pessoa", na qual o direito também se apoia para instituir direitos. Reale (2002) define pessoa como um "valor fonte" de valores, peça chave de fundamentos jurídicos, cuja aplicação na legislação brasileira podemos ler como uma existência humana para gozo efetivo de direitos referentes à personalidade. Gonçalves (2011) aponta ainda que a pessoa, possuidora de capacidade civil e detentora de direitos inerentes à personalidade, é também chamada de pessoa natural, uma vez que se elenca diretamente à fonte originária, isto é, o ser humano.

A condição de pessoa natural de direito sustenta-se em dois requisitos básicos elencados por nossa legislação: nascer com vida e ser um humano. Tais critérios são necessários para o indivíduo exercer sua cidadania e civilidade dentro do coletivo, ou seja, não somente no aspecto filosófico, mas prático dentro da sociedade de direito. De modo complementar, este ser essencialmente político dita, mesmo que indiretamente, moralidade e direito para a sociedade, sendo o agente catalisador de qualquer valor e pivô do ordenamento jurídico (REALE, 2002)

O conceito de pessoa humana como um ente universalmente aceito é algo novo, afirma Comparato (2015). Entretanto, a mesma ideia de ser humano ainda sofre com a ausência de uma fonte rígida. Enquanto uma existência dialética, o sentido e a conceituação de "ser humano" utilizados para atribuir a um "ser" a condição de "humano" e pertencente a um grupo de seres humanos assumiu o termo "homem" como referente, atribuindo aos "estranhos" a este coletivo algumas denominações diversas, quase que pertencentes a outra espécie. Neste sentido, a cognição de igualdade entre os seres humanos, pelo fato de sua humanidade, advém historicamente da lei escrita e difundida, e modo uniforme e isonômico para os indivíduos de uma sociedade (COMPARATO, 2015), contudo não resolveu a questão de reconhecimento de forma plena quando as diferenças são observadas do ponto de vista do próprio indivíduo enquanto agente de uma discursividade. 
A flexibilidade tanto do reconhecimento do ser humano quanto da sustentação deste no tempo e no espaço social abrem um caminho para a discussão de conteúdos explícitos em legislações infraconstitucionais, cuja vertente adotada neste artigo é a problematização do termo "mulher". Uma vez considerando que a constituição do discurso sobre o ser humano aponta para uma figura do homem como fundador, admite-se que este tenha moldado a sociedade com base em seus anseios e desejos. O termo "homem" aqui empregado, por mais que se refira ao coletivo humano, é, de certo modo, representante de uma parte destes.

Como detentor do poder de escolha na maior parte da história humana, o homem definiu como as leis deveriam ser feitas, como os costumes seriam aplicados, e assumiu o termo de autorreferência como termo a ser empregado para o coletivo. Tal concepção aponta para uma certa percepção de poder na constituição de referenciais societários. Brasil (2017) sustenta concepção cômpar ao observar na legislação civil brasileira o vocábulo "mulher", cuja concepção está atrelada a uma dominação essencialmente patriarcal, que concede poderes de imposição e validação da autovontade ao homem quando comparado à mulher. A autora registra ainda que o locus desta só foi alterado em 2002, com o advento do novo código civil que substitui uma legislação com quase cem anos de vigência.

Para compreender o significado de mulher dentro do contexto legal infraconstitucional, a pesquisa descritiva atende à caracterização deste ser de direitos de modo a contribuir com o contexto doutrinário, agregando-lhe novos aspectos, trazendo à baila um estado da arte sobre um determinado elemento, o qual Gil (2002) concebe como um tipo de discussão que permite apontar a criação de um elo entre relações e variáveis. Deste modo, no que se refere a seus objetivos, a pesquisa descritiva elenca uma série de fatos históricos, e os associa com o mundo legal infraconstitucional de direitos sociais pós 1988.

No que se refere ao método utilizado, assumimos o hipotético-dedutivo elucidado por Popper (2013), a qual permite enunciar uma certa verdade que se aproximava da universalidade porém numa forma de conjectura e provisoriedade da solução proposta, ou seja, tendo como base as afirmações e hipóteses enquanto assertivas que são testadas e cujos resultantes podem ser favoráveis ou não às preposições, esta pesquisa sobre a "mulher" assume possibilidades e discrepâncias entre o termo aplicado no direito e a realidade social.

Ainda em relação à metodologia utilizada nesta pesquisa cujo recorte dá-se nos direitos sociais infraconstitucionais pós 1988, é relevante registrar sua natureza qualitativa que serve à compreensão da singularidade legal em meio a uma revisão do termo mulher dentro da lei, criação de hipótese coerente, elaboração de uma narrativa com novas descobertas e relevâncias ao objeto e contextualização de um relato sempre provisório (MINAYO, 2012), ou seja, a interpretação dos conteúdos (termos) permite a construção de um sentido conceitual de mulher enquanto sujeito de direito na própria situacionalidade dos documentos utilizados e a realidade social observada.

Quanto à lógica de definição de espaços sociais dos indivíduos em questão, vale a pena observar o significado de poder que está intrínseco à problemática de quem são os indivíduos. Tal conceito pode ser compreendido enquanto toda probabilidade de impor-se, em vontade, numa situação relacional, que no caso seria entre pessoas (WEBER, 2000). Todavia é necessário que, diante da própria complexidade social, este poder seja asseverado em uma forma difusa e sustentadora de um controle social, mesmo diante de resistências. 
Na visão de Foucault (1999) este mesmo poder existe para além de uma estrutura central e única verticalizada, pois, de fato, deve ser visto como micropoderes, inclusive em sua forma biologizante. Ao contexto desta pesquisa, cabe suscitar o termo biopoder para problematizar a concepção de mulher no âmbito legal, dada perspectiva foucaultiana que o entende como mais uma forma de exercer o controle sobre a população através de preceitos biológicos. Derivativo de um longo processo histórico de definição dos indivíduos, tal lógica não é uma criação moderna, mas remonta à própria constituição da sociedade, sendo apenas demonstrada na contemporaneidade por meios até sutis de controle e vigilância.

Conforme preconiza o referido autor, por volta do século XVII, o advento de excepcionais técnicas de medicina juntamente com o avanço da pesquisa científica, a sociedade humana foi concebida como seres formados por impulsos biológicos e os homens utilizaram-se destes preceitos para a auto manutenção sobre a mulher (FOUCAULT, 1999). Numa interpretação deste exercício do biopoder no campo do direito assumimos neste artigo a estruturação da figura mulher como uma pessoa de direito em uma forma específica, isto é, de direito condicionado, buscando entender como a legislação em questão apresenta a "mulher".

\section{A SUBMISSÃO FEMININA E A DISSOCIAC̣ÃO DA IDEIA DE GÊNERO E SEXO}

Dentro da perspectiva de micropoderes adotada neste artigo, as questões associadas ao feminino, gênero e sexo são tomadas como construções sociais cujas significações evocam pontos de vistas ímpares ante à centralidade de quem é o indivíduo de fato. Logo, é importante definir "quem é quem" no jogo relacional para então delimitar nos personagens o reconhecimento de agência de cada um na sociedade.

Para compreender esta problemática em face do direito, assumimos que o próprio direito emana de fato, valor e norma (REALE, 2002) e que este também é uma forma de controle (FOUCAULT, 1999), cujo poder é exercido por alguém em posição de dominar enquanto outro é dominado. A episteme dicotômica aqui expressa e admitida em face os termos homem e mulher segrega estes seres humanos por condições inerentes ao sexo biológico, o qual ainda se confunde com o conceito de identidade de gênero no senso comum, como pondera Beauvoir (2002).

Sob tal égide, nota-se que indivíduos são produzidos e reprimidos dentro de moldes sociais, os quais inviabilizam uma liberdade, fundado em um discurso de opressões e auto centrado em uma figura masculina, cujo aporte encontra-se em Butler (2003) ao reiterar a existência de uma relação próxima entre o movimento feminista e a caracterização de sujeito submisso, cuja ideia de violência contra a mulher da sociedade primitiva assume a forma de um pacto social de voluntariado para o que é "ser homem" e o que é "ser mulher".

No contexto familiar, evidencia-se uma dominação do homem e uma centralidade de si, constituída ao longo do tempo numa posição de superioridade sobre filhos e esposa, apontando ainda para uma prevalência da submissão feminina como singular e universal (WEBER, 1982). Em relação a esta dicotomia, Beauvoir (2002) pondera que o homem edificou-se enquanto figura de desenvolvimento histórico, mantendo a mulher como alguém do mundo doméstico e da família; mesmo que inicialmente isto tenha se dado de modo inconsciente, afirma a autora, a mulher adquiriu a forma de uma "organela da unidade morfofisiológica da sociedade", ou seja, uma parte da sociedade com papel específico. Deste modo, um discurso 
se constitui na sociedade apoiando a figura mítica da mulher como materna, submissa, frágil e até menos inteligente.

Garcia (2009) alega que a condição da mulher mudou diversas vezes no decorrer dos tempos, iniciando com o status de inferioridade e obediência ao marido, pontuado de lutas vorazes na conquista de direitos, até a ascensão da autonomia individual e inserção a grupos hegemônicos. Contudo, a condição somenos da mulher, ressaltada por Beauvoir (2002), a qualifica como um subproduto da espécie humana. De modo crítico, esta autora posiciona-se contra a tradição social do que é "ser mulher" e argumenta a favor da diferenciação do que é mulher e fêmea humana, ou mesmo de um processo de (re)criação deste sujeito. Em sua defesa, argumenta que o homem suscitou a regulação e ajuizamento da própria noção (não equivalente) de mulher, sendo o protagonista passível de compreensão no âmbito jurídico como parte e juiz em causas.

Diante de uma compreensão histórica de quem são as partes envolvidas no próprio processo, a neutralidade axiológica dos termos mulher e homem aponta para uma instabilidade na equivalência destes. Tangente ao posicionamento social de gênero, o lugar neutro do próprio direito da pessoa humana prescinde de uma revisão crítica, dado que se reverbera uma dialética subalternizante da figura mulher. Ao que cabe, Beauvoir (2002) e Butler (2003) opõem-se a uma associação comum entre os termos mulher e fêmea, sendo a primeira um ser social e a segunda uma entidade biológica.

Em breve digressão sobre a histórica, Friedan (1971) sinalizou o impacto da primeira onda feminista no final do século XIX a respeito de direitos da mulher. Nessa época, a luta pelo sufrágio ou mesmo o ingresso ao ensino superior pelas mulheres foram constantes, entretanto, tal militância teve parte de sua essência de luta dissipada em meados do século XX. A autora apresenta como principal agente cáustico o grande bombardeio da mídia na criação da "da mulher perfeita", a qual se mostrou nociva para as praticantes dos inúmeros hábitos reificadores de um padrão estético e comportamental.

O retrocesso para a mulher nesse período também esteve associado a questões econômicas e culturais. A imagem da mulher "de família" começou a ser vendida depois da segunda guerra mundial, tendo as revistas e programas de rádio como suportes e veículos de propagação do ideal de mulher perfeita, do lar e apoiadora do marido. Este arquétipo da mulher seguiu amparado então pela volta da mesma à cozinha, pelo comportamento e padrão de beleza ditados pelas revistas da época. Em sua análise sobre o século XX, Beauvoir (2002) compreendeu que para as mulheres a escolha mais fácil era calar-se diante da iniquidade, uma vez que fugir do paradigma imposto lhes acarretaria uma forte represália.

Outra mística feminina cujo aporte é feito por Friedman (1971) pauta-se numa postura reduzida da mulher, ora engrandecendo o "estado" de mulher, ora elencando os privilégios que possuía em relação às donas de casa de outro países fora dos Estados Unidos, sendo a mulher estadunidense multifacetada, possuidora das capacidades de gerente, enfermeira, não havendo tanta necessidade de ingresso na vida universitária.

A mesma autora cita que as mulheres que possuíam o maior nível de insatisfação eram as que ostentavam maior grau de formação. O pensamento de ter perdido sua carreira, vida e identificando-se em favor do ideal feminista as levavam ao estado de depressão, tornando-as vítimas do mal que afligia donas de casa. Nota-se que a mulher estava farta de ser mulher, 
e a condenação por nascer fêmea lhe garantia unicamente este papel na sociedade (FRIEDMAN, 1971). As mais velhas lamentaram por não ter vivido suas vidas de maneira legítima, somente podendo sonhar que suas filhas o fizessem. Peculiarmente, os problemas elencados até o presente desta discussão apontam para uma ideia de mulher associada com o gênero feminino, como uma condenação natural e social, cujo corpo reifica uma natureza de mulher lastreada na biologia e no dever ser.

Em oposição a esta concepção aprisionante, Butler (2003) invoca preceitos para a desconstrução de ideais imputados à mulher. A problemática se ergue mediante a estrutura de formação do eu humano, no qual a alteridade sempre precisou da dualidade para conceituar o eu. De fato, a autora se apoia nas discussões sobre identidade, a qual se dá enquanto uma diferenciação de algo que não se é. Todavia, traz à tona a crítica da estrutura fundante de quem é esta personagem na medida em que ao tratar de homem e mulher, as defesas acabam objetificando uma dualidade distinta dos entes com caracterizações de desigualdade que se firmam num natural e lógico; o aprofundamento além da aparência que estaria num discurso crítico sobre a política de definições das coisas, a qual aponta para um deslocamento deste padrão de ser-essência, parece apenas como um signo discursivo de conteúdo não-hierarquizante vazio na sociedade.

Assim, a aceitação de uma reflexão sobre "gênero" está mais ligada com a ideia de desconstrução de uma estrutura fixa como a que se interpõe ante à reflexão de quem "é" a mulher, inclusive diante da explícita referência de Beauvoir (2002) a respeito de não nascer-se mulher, mas torna-se mulher. É nesta tentativa de desnaturalizar o ser que a pesquisadora levanta o princípio de igualdade, e que nos serve à problematização da mulher na legislação infraconstitucional pós 1988 perante os direitos sociais.

\section{A FIGURA DA MULHER NA E PÓS CONSTITUIÇÃO DE 1988}

Conforme redação do artigo $6^{\circ}$ da Constituição de 1988, elencam-se entre os direitos sociais republicanos "a educação, a saúde, a alimentação, o trabalho, a moradia, o transporte, o lazer, a segurança, a previdência social, a proteção à maternidade e à infância, a assistência aos desamparados", os quais Silva (2010) compreende como prestações positivas, direta ou indiretamente prestadas pelo Estado de Direito. Por sua emanação de uma constituição de um povo, tais direitos visam a viabilização de melhores condições de vida aos mais fracos prezando pela equidade, proporcionando condições favoráveis para pessoas em situações distintas exercerem efetivamente sua liberdade, independentemente de sua condição social, de gênero, raça, educacional, etc.

Tal Constituição inova com o título de Constituição Cidadã, afirmando em seu corpo ideais de igualdade, poucas vezes vistos nas constituições anteriores de forma explícita. Garcia (2009) afirma que esta é uma tendência de constituições pós segunda guerra, expressando ainda elementos de justiça, os quais decorrem da percepção do histórico inegável de desigualdades, e neste sentido, a igualdade de gênero recebe luz. Cabe lembrar que no Brasil, até a constituição de 1934, a igualdade entre gêneros não havia sido expressamente incorporado ao texto legal (BRASIL, 1934).

Já no âmbito dos direitos pós 1988, a Comissão Nacional de Mulheres Advogadas aponta noventa e um textos de cunho legal onde o termo mulher está registrado, dentre leis e 
decretos, todos inerentes a direitos femininos. No que tange ao objeto desta pesquisa, sessenta e nove enquadram-se entre 1988 e 2010 , período equivalente a pouco mais de vinte anos da promulgação da constituição cidadã, sendo que o documento mais antigo que evidencia o termo mulher data de 1990, isto é, no segundo ano após a promulgação a citada constituição.

Em vigência, verifica-se que há cinquenta e cinco delas pós 1988, dentre as quais, somente vinte e nove fazem menção direta ao termo "mulher", e somente vinte enquadram-se no recorte problematizado dos direitos sociais para o período de definido neste artigo, as quais são abordados pontualmente em seguida.

A primeira aparição do termo num texto legal pós-constitucional se dá na lei $\mathrm{n}^{\mathrm{o}} 8.112$, de 11 de dezembro de 1990, que dispõe sobre o regime jurídico específico para servidores públicos civis da união, além de autarquias e fundações públicas federais, no qual o artigo 186, $\S 3^{\circ}$, alíneas a, c e d incumbem um tempo de contribuição diferenciado à mulher, de 5 anos a menos em relação ao homem.

Em seguida, tem-se a lei no 8.213, de 24 de julho de 1991, que se encarrega de elencar diretrizes para benefícios da Previdência Social e dá outras providências. As menções ao termo mulher são encontradas em alguns artigos. No artigo 29, parágrafo nono inciso I, registra-se que à contagem do tempo de contribuição da mulher somam-se mais cinco anos ao fator previdenciário no tocante a seu salário-de-contribuição. Tal inclusão dá-se pela lei $\mathrm{n}^{\mathrm{o}} 9.876$, de 26 de novembro de 1999. Já o artigo 29-C da lei em questão, cujo texto dá-se por inserção segundo a lei 13.183 de 4 de novembro de 2015, apresenta mais uma diferenciação em relação à previdência da mulher. As contribuintes que apresentam o tempo de contribuição preenchido podem facultar no que tange à incidência do fator previdenciário no cálculo de sua aposentadoria, isto é, as mulheres tem como requisito cinco anos a menos que os homens, sendo de trinta para elas e trinta e cinco para eles.

O artigo 48 da supracitada lei exibe ainda os requisitos para aposentadoria por idade, sendo à mulher assegurado o direito de se aposentar, também neste quesito, com cinco anos a menos que o homem. O parágrafo $1^{\circ}$ deste artigo também privilegia pessoas para aposentadoria rural segundo o critério de idade, que, de igual modo, a mulher se aposenta com menos cinco anos; a mesma lógica está expressa também no artigo 53.

Já no artigo 120, inciso II, há uma associação entre direitos sociais e violência contra a mulher, cujo texto apresenta a possibilidade de ação regressiva contra o agressor doméstico que der causa para o afastamento remunerado. A medida contextualiza-se como fator educativo em virtude da punibilidade do agente causador. Contudo, o intuito econômico ainda se encontra enraizado na essência da medida, estando o pagamento prestacional à Previdência Social explícito no artigo subsequente a este. Outrossim, no artigo 122 o texto legal volta a referenciar a mulher diante do tempo diferencial de contribuição, questão esta dentro da facultatividade da aposentadoria, em redação dada pela lei no 9.528 de 10 de dezembro de 1997.

A lei ${ }^{\circ}$ 8.742, de 7 de dezembro de 1993, que dispõe sobre a organização da assistência social e dá outras providências, no artigo 40-A prevê que os benefícios eventuais, o benefício do Programa de Erradicação do Trabalho Infantil (PETI) e os Projetos de Enfrentamento da Pobreza serão pagos preferencialmente à mulher responsável pela unidade familiar. A associação explícita do termo mulher como "chefe" traz consigo uma possível reconstrução do espaço social desta personagem em face das configurações familiares atuais e da constatação 
de famílias chefiada por mulheres, ou ainda prefigura outro problema social de condições econômicas diferenciais para homem e mulher no contexto social, algo não explícito no conteúdo legal, mas próprio ao discurso social ancorado em Butler (2003).

No quesito saúde, a primeira menção à palavra mulher encontra-se na lei $n^{\circ} 8.069$, de 13 de julho de 1990, que dispõe principalmente sobre o Estatuto da Criança e do Adolescente (ECA). O termo em questão, explícito no artigo $8^{\circ}$ da citada Lei, conta sobre a seguridade de acesso da mulher ao programa de planejamento reprodutivo, este que é melhor abordado no artigo $2^{\circ}, 3^{\circ}$ e 10 da lei $n^{\circ} 9.263$, de 12 de janeiro de 1996. A principal discussão acerca destes dispositivos encontra-se na liberdade reprodutiva. No artigo 10 o conteúdo associado à mulher limita a opção de reprodução a anuência do cônjuge, desconsiderando o direito individual em razão do casal, permitindo-nos ponderar sobre o valor de decisões individuais e pessoais contextualizando a discussão de Brasil (2017) sobre a posição desta figura de direito.

A "mulher" também se encontra na definição de entidade familiar no artigo $1^{\circ}$ da lei 9.278 de 10 de maio de 1996, cuja concepção de vínculo social implica em convivência duradoura, pública e contínua, de um homem e uma mulher, estabelecida com objetivo de constituição de família.

Um relevante interposto conceitual entre a lei $\mathrm{n}^{\circ} 8.742$, de 7 de dezembro de 1993 e a lei $n^{\circ} 9.263$, de 12 de janeiro de 1996 é a concepção de unidade familiar, dada como uma forma organizacional da sociedade que implica um vínculo entre mulher e homem, na segunda lei, regulamentando o parágrafo $7^{\circ}$ do artigo 226 da Constituição vigente, e açambarcando a lei de 1993, cuja atenção da política pública é dada à mulher, ao homem e ao casal, nesta sequência.

Tal conteúdo manifesto evoca uma semântica cuja inferência da mulher como agência no âmbito doméstico-familiar dá-se pelo contexto histórico e social no qual ancora-se a figura feminina butleriana. Ainda no ECA, os artigos $8^{\circ}$ e 14 apresentam mais uma forma de apoio à saúde da gestante e mulher com criança na primeira infância, a qual deve ser dada pelo poder público, mesmo diante de contexto de privação de liberdade.

Há nessa lei uma equiparação entre os termos gestante e mulher no âmbito da saúde. Em sentido diverso ao presente nos artigos citados, a lei $\mathrm{n}^{\circ} 11.664$, de 29 de abril de 2008, lança mão unicamente do termo mulher, atribuindo-lhe a noção de sujeito em si, inclusive sendo atendido em sua especificidade de saúde, o que ressalta uma relevância implícita, cuja riqueza dá-se numa análise do próprio conteúdo explícito (FRANCO, 1986).

Recuperando o ECA, o termo mulher vincula-se com a noção de "mãe", excetuando-se tal semântica nas disposições gerais do capítulo III, quando apresenta significações díspares para gestante e mãe. Contudo, denota-se um papel histórico da mulher fora da igualdade legal nesta Lei quando observada a problemática até 2009. Neste ano houve a substituição de um importante referente de poder no texto legal. À mulher (mãe), mesmo objetivamente citada em igualdade de condições no que se refere ao cuidado com a criança, era-lhe negado subjetiva e historicamente a mesma condição de poder equiparado na unidade familiar, vista expressão "pátrio poder" vigente até a alteração terminológica para "poder familiar".

O termo "pátrio" traz consigo uma estrita relação com o tipo de poder patriarcal no qual a definição de mulher espelha-se hierarquicamente diminuta. Neste sentido, é possível associar-nos a Foucault (1991) ao alegar que a padronização de comportamentos nos pares 
de sociedades patriarcais estabeleceu ao homem as atribuições de efetivo mantenedor e viril, enquanto a mulher performou-se pela feminilidade e maternidade. Em vias gerais, como apresentado por Friedan (1971), estes papéis predefinidos foram os responsáveis pela disseminação da mística feminina.

Dentro dos direitos sociais outra preocupação é registrada: a mulher gestante ou sob risco de engravidar. Uma vez nesta condição, a mulher recebe atenção também nas leis $\mathrm{n}^{\circ}$ 10.651, de 16 de abril de 2003 e no 11.804 , de 5 de novembro de 2008, a primeira quanto ao medicamento talidomida e o segundo sobre os alimentos gravídicos. Ambas esboçam preocupação que sobrevém à mulher enquanto mantenedoras da prole, complementando não somente direitos, mas também obrigações no que se refere à vida humana durante o processo de gestação.

Nas leis $\mathrm{n}^{\circ} 8.629$, de 25 de fevereiro de 1993, $\mathrm{n}^{\circ} 10.836$, de 9 de janeiro de 2004 e no Decreto $\mathrm{n}^{\circ} 4.675$, de 16 de abril de 2003, o legislador assegura à mulher a preferência no recebimento de benefícios como bolsa família, reforma agrária e cartão alimentação. Tal condição preferencial traz à baila uma relevante reverberação do lugar da mulher no imaginário social de responsável por cuidados no mundo doméstico. Entretanto, dada a abrangência de uma discussão e latente cenário de famílias chefiadas por mulheres, cabe outra reflexão, o que provocaria um desvio neste artigo.

Outra importante Lei no período coberto por esta pesquisa que problematiza o lugar da mulher no texto legal é o Estatuto da Desigualdade Social (Lei n ${ }^{\circ} 12.288$, de 20 de julho de 2010). Este aparato visita uma relevante discussão sobre interseccionalidade, cujo sentido dado por Piscitelli (2008) é a interação dos meios de dominação, como o racismo, sexismo e o próprio patriarcalismo. No caso, o texto da Lei registra uma mulher negra, que só foi entendida como dependente de proteção, no que tange a discriminação racial e por gênero, em 2010.

Embora os construtos sociais histórico-conflitivos atribuídos à população negra sejam o foco e o texto legal incorpore a questão da intolerância racial ou étnico-racial perante a qual se estatui um discurso de mitigação das desigualdades históricas e fortaleça as ações afirmativas como políticas focais, é apenas no artigo 63 que registra-se uma definição de violência contra a mulher de modo generalizante, ou seja, como qualquer ação ou conduta, baseada no gênero, inclusive decorrente de discriminação ou desigualdade étnica, que cause morte, dano ou sofrimento físico, sexual ou psicológico à mulher, tanto no âmbito público quanto no privado. Este texto reescreve a lei $\mathrm{n}^{\circ} 10.778$, de 24 de novembro de 2003 , que tratava propriamente da violência contra a mulher.

Por fim, mesmo não sendo um direito social em si, identifica-se neste período a lei $\mathrm{n}^{\circ}$ 10.745, de 9 de outubro de 2003 que determina o ano de 2004 como o ano da mulher. Conforme publicação do Ministério da Saúde (2004), além do teor honroso, o intuito deste ano estava envolto à congratulação das conquistas femininas, além de consolidar iniciativas de inserção cível da mulher na sociedade brasileira. Este ato revela indícios pontuais de igualdade na prática, bem como de justiça, por meio de programas e atividades a serem realizadas pelo próprio poder público.

\section{OUTROS PONTOS, ALGUMAS CONSIDERAÇÕES}

A definição e a reivindicação de direitos sociais tornam clara a existência de uma disparidade temporal entre as necessidades da sociedade e a efetiva implementação de um direito, 
num movimento constante e ancorador das partes, até mesmo dentro da discussão de gênero aqui presente. Os dispositivos levantados neste artigo, perfazendo um período de pouco mais de vinte anos após a promulgação da Constituição Cidadã, revelam questões importantes quanto à mulher como um sujeito de direitos diante do legislador e do Estado.

Em um esforço de caracterização do espaço social da mulher para então compreender sua forma na legislação infraconstitucional, identificamos no Relatório socioeconômico da Mulher (lei 12.227 de 12 de abril de 2010), um ponto tardio no escrutínio de direitos sociais próprio à mulher. A partir desta pauta tal personagem passa então a ser objeto de estudo do governo federal com o intuito de entender de maneira ampla seu cotidiano.

O cenário de emprego e renda no qual está inserida, por exemplo, observado no âmbito legal com referência explícita a um tempo menor de trabalho no tocante aos direitos sociais, tem como fator relevante na sociedade brasileira uma certa desigualdade quando comparada ao trabalho do homem.

Numa leitura contextualizada, há uma duplicidade na jornada de atuação cotidiana da mulher, denotando não somente a presença predominantemente feminina em atividades domésticas, como também um prolongamento dela. Spinola (2003) caracteriza tal multiplicidade de jornada como sendo a junção de atividades domésticas, profissionais, registrando as mulheres enquanto sujeitos-tipo desta estrutura social do trabalho. Contudo, complementa que não são contabilizadas as jornadas reais de trabalho excedente de mulheres. Outro aspecto relevante dá-se na observância de que esta não é maioria no mercado predominantemente masculino e ainda recebe $3 / 4$ do salário dos seus concorrentes, conforme IBGE (2018).

Em suma, quando se fala de trabalho, Costa (2018) descortina o cenário da mulher atribuindo-lhe a característica de ser "ambivalente", reafirmando a complexa combinação da emancipação feminina quando tal personagem situa-se entre a autoafirmação no mundo do trabalho e o papel de mãe na esfera privada. Embora tenha cada vez mais conquistado seu espaço na esfera social (BRUSCHINI, 1999), a mesma vivencia uma ambiguidade em sua representação social perante o princípio de equidade.

Em atenção aos dispositivos que tratam de direitos quanto a saúde, é perceptível uma vinculação ao "materno" como termo que tipifica o vocábulo mulher. Tais leis, que são a maioria nesta pesquisa, tiveram uma priorização na última década do século $\mathrm{XX}$, cenário este no qual a mulher ainda era considerada como parte essencial da reprodução humana, em detrimento de seus direitos individuais. A terminologia presente nos documentos legais em voga reitera inúmeras vezes a ideia da mulher como uma possível mãe.

Dados da Organização Mundial da Saúde (OMS) de 2014 apontam que o número de casos de mulheres que sofrem qualquer tipo de violência antes, durante e depois do parto, sendo esta de qualquer natureza, desde maus tratos e procedimentos não autorizados, como esterilização, ataques verbais que acontecem à mulher em trabalho de parto, tais fatos avançam numa tendência crescente ao redor do mundo. Ao que cabe, a legislação brasileira assegura à gestante meios de garantir a continuação da vida, o que de fato se apresenta de maneira prioritária até mesmo em relação à integridade física da mulher, conforme a Lei de Planejamento Familiar ou o próprio ECA; ainda que nem sempre a integridade da mulher seja respeitada, conforme se tem noticiado com o crescente aumento de casos documentados pela OMS de violência obstétrica, perante a lei, ela o é. 
O mesmo direito brasileiro que avança em suas propostas para uma positivação de direitos da mulher, ainda é omisso quanto a questões considerada polêmicas, inclusive, quanto ao aborto de fetos anencéfalos (ARAÚJO, 2018), ponto transversal e de grande relevância à saúde desta. Logo, em consideração às legislações aqui trabalhadas, percebe-se que o debate da liberdade reprodutiva é abordado de maneira restritiva à escolha da mulher, ou seja, cabe uma anuência do homem.

Como um indivíduo de direitos, a mulher perante a legislação social brasileira no período de 1988 a 2010 tende a uma vinculação com a prefigura doméstica, com forte associação à manutenção da unidade familiar; bem como de um "ser materno", levando em consideração a quantidade de dispositivos que tendem a priorizar a saúde da mulher enquanto gestante. Entretanto, é possível perceber uma sensível mudança no discurso legal ao levar em consideração a declaração do ano de 2004 como o Ano da Mulher, uma ação simbólica para combater violência contra elas, inclusive com indícios explícitos no conteúdo do texto que apontam para o reconhecimento do indivíduo como fonte de valor desta parcela da população.

No anteposto período do desenvolvimento legal, percebe-se a problematização relativa a quem é a mulher pode ser tipificada em três grandes áreas: Mulher e Saúde (1990 - 2000), Mulher e Violência (2000 - 2010) e Mulher e Social (2010 em diante). Todavia, a capacidade do texto legal em promover uma nova prática social deve ser analisada detidamente, visto que sua inscrição nos "corpos" ou o texto radicar-se em mudanças sociais de ampla e histórica profundidade enfrenta pressões de diferentes ordens.

Sobre a inexistência formal e explícita de barreira e domínios sobre a mulher em diferentes dispositivos legais é necessário recuperamos a simbologia bourdiesiana na seguinte assertiva: “...a autoexclusão e a vocação [...] vêm substituir a exclusão expressa” (1998, p. 52); isto é, a admissão pública, formal, coletiva, política ou de qualquer outra natureza que negue a existência de diferenças de valor entre indivíduos, reforça as reverberações e predisposições tácitas de uma violência simbólica já inscrita nos corpos, e silenciadas pelo texto legal.

Deste modo, entendendo a evolução legal dentro do recorte desta pesquisa mas não nos restringindo estritamente ao conteúdo dos dispositivos legais, nota-se que a mulher, um sujeito de direitos, carrega em "si" um discurso consolidado "sobre si", o que na terminologia de Rocha-Coutinho (1994) seria uma "natureza feminina", que está referenciada por um tipo de cuidado familiar, cuja vivência disciplinadora remonta historicamente a constituição da sociedade colonial brasileira. (DEL PRIORE, 2004)

Mediante a tendência do legislador brasileiro em seguir uma linha mais humanizada, a conciliação do indivíduo de valor e o espaço histórico-legal da mulher no direito positivado infraconstitucional pós 1988 que sinaliza a equidade pacificada em lei, tal comportamento legal pode ser lido na perspectiva bourdiesiana como uma forma estruturante e ao mesmo tempo estruturada de uma dominação masculina, com atribuições de papéis sociais a cada indivíduo (1998), mesmo diante de um discurso que se pretende neutro, o qual se apresenta, por força, como legítimo.

Assim, sem findar a discussão sobre o tema, admitindo que a partir de 2000 tenha nascido um discurso mais substancial no direito quanto a proteção à mulher e que as legislações referentes à mulher criaram mecanismos para combater a violência doméstica, apontando ainda para uma atenção à mulher no mercado de trabalho, nesta breve digressão identifica- 
mos a existência de uma polifonia de conteúdo que explicita uma concepção ambígua de mulher; uma imprecisão das amarras simbólicas no direito social mediante o controle dos "corpos" sobre quem é (são) a(s) mulher(es).

\title{
THE WOMAN SEEN THROUGH SOCIAL RIGHTS IN BRAZILIAN LEGISLATION AFTER THE 1988 CONSTITUTION.
}

\begin{abstract}
This paper aims to build a generalized characterization of women as a subject of law in analytical perspective, raising its social role concerning onerosity and rights under a Brazil's inherent social rights legislation after Federal Constitution of 1988. Focusing on National Commission for Women Lawyers survey, through the prerogatives reasoned in feminist movement, an attempt to define a figure called woman. Based in gender debate, in addition to the differentiation of gender and sex idea as well as dialectic domination, powers and intersectionality.
\end{abstract}

KEYWORDS: Constitution. Gender. Law. Right. Woman.

\section{BIBLIOGRAFIA}

ALVES, José Eustáquio Diniz. Desafios da equidade de gênero no século XXI. Revista de Estudos Feministas, Florianópolis, v. 2, n. 292, p. 629-638, ago. 2016.

ARAÚJO, Andréia Matias. A judicialização da política e os direitos fundamentais no congresso nacional: uma análise da adpf 132/rj e da ADPF 54/DF no Supremo Tribunal Federal e na Câmara dos Deputados. 2018. 119 f. Dissertação (Mestrado) - Curso de Poder Legislativo, Centro de Formação, Treinamento e Aperfeiçoamento da Câmara dos Deputados/CEFOR, Brasília, 2018.

BEAUVOIR, Simone de. O segundo sexo. Rio de Janeiro: Nova Fronteira, 2002.

BOURDIEU, Pierre. A dominação Masculina. Rio de Janeiro: Bertrand Brasil, 1998.

BUTLER, Judith. Problemas de Gênero: Feminismo e subversão da identidade. Rio de Janeiro: Civilização Brasileira, 2003.

BRASIL. [Constituição de (1934)]. CONSTITUIÇÃO DA REPÚBLICA DOS ESTADOS UNIDOS DO BRASIL, 1934. Rio de Janeiro: RJ, Presidência da República. Disponível em <http://www. planalto.gov.br/ccivil_03/Constituicao/Constituicao34.htm>. Acesso em: 28 abr. 2019.

[Constituição de (1988)]. CONSTITUIÇÃO DA REPÚBLICA FEDERATIVA DO BRASIL DE 1988. Brasília, DF: Presidência da República. Disponível em: <http://www.planalto. gov.br/ccivil_03/constituicao/constituicaocompilado.htm>. Acesso em: 28 abr. 2019>. Acesso em 28 de abr. 2019.

LEI No 8.069, DE 13 DE JULHO DE 1990. Dispõe sobre o Estatuto da Criança e do Adolescente e dá outras providências. Diário Oficial da União, Brasília, DF, 13 de jul de 1990. Disponível em: <http://www.planalto.gov.br/ccivil_03/leis/18069.htm>. Acesso em 14 de fev. 2020.

LEI No 8.080, DE 19 DE SETEMBRO DE 1990. Dispõe sobre as condições para a promoção, proteção e recuperação da saúde, a organização e o funcionamento dos serviços correspondentes e dá outras providências. Diário Oficial da União, Brasília, DF, 19 de set de 1990. Disponível em: <http:// www.planalto.gov.br/ccivil_03/leis/18080.htm>. Acesso em 14 de fev. 2020.

LEI No 8.112, DE 11 DE SETEMBRO DE 1990. Dispõe sobre o regime jurídico dos servidores públicos civis da União, das autarquias e das fundações públicas federais. Diário Oficial da União, Brasília, DF, 11 de set de 1990. Disponível em: <http://www.planalto.gov.br/ccivil_03/leis/ 18112compilado.htm>. Acesso em 14 de fev. 2020.

. LEI N N $^{\circ} .213$, DE 24 DE JULHO DE 1991. Dispõe sobre os Planos de Benefícios da Previdência Social e dá outras providências. Diário Oficial da União, Brasília, DF, 24 de jul de 1991. Disponível em: <http://www.planalto.gov.br/ccivil_03/leis/18213cons.htm>. Acesso em 14 de fev. 2020.

LEI N 8.629, DE 25 DE FEVEREIRO DE 1993. Dispõe sobre a regulamentação dos dispositivos constitucionais relativos à reforma agrária, previstos no Capítulo III, Título VII, da Constituição Federal. Diário Oficial da União, Brasília, DF, 23 de fev de 1993. Disponível em: <http://www.planalto.gov.br/ccivil_03/leis/18629.htm>. Acesso em 14 de fev. 2020.

LEI No 8.742, DE 7 DE DEZEMBRO DE 1993. Dispõe sobre a organização da Assistência 
Social e dá outras providências. Diário Oficial da União, Brasília, DF, 7 de dez de 1993. Disponível em: <http://www.planalto.gov.br/ccivil_03/leis/18742.htm>. Acesso em 14 de fev. 2020.

LEI No 9.263, DE 12 DE JANEIRO DE 1996. Regula o $\S 7^{\circ}$ do art. 226 da Constituição Federal, que trata do planejamento familiar, estabelece penalidades e dá outras providências. Diário Oficial da União, Brasília, DF, 12 de jan de 1996. Disponível em: <http://www.planalto.gov.br/ ccivil_03/leis/19263.htm>. Acesso em 15 de fev. 2020.

LEI No 9.278, DE 10 DE MAIO DE 1996. Regula o $\S 3^{\circ}$ do art. 226 da Constituição Federal. Diário Oficial da União, Brasília, DF, 10 de maio de 1996. Disponível em: <http://www.planalto.gov. br/ccivil_03/LEIS/L9278.htm>. Acesso em 15 de fev. 2020.

LEI No 9.434, DE 4 DE FEVEREIRO DE 1997. Dispõe sobre a remoção de órgãos, tecidos e partes do corpo humano para fins de transplante e tratamento e dá outras providências. Diário Oficial da União, Brasília, DF, 4 de fev de 1997. Disponível em: <http://www.planalto.gov.br/ccivil_03/ leis/19434.htm>. Acesso em 15 de fev. 2020.

LEI No 10.651, DE 16 DE ABRIL DE 2003. Dispõe sobre o controle do uso da talidomida. Diário Oficial da União, Brasília, DF, 16 de abril de 2003. Disponível em: <http://www.planalto.gov. br/ccivil_03/Leis/2003/L10.651.htm>. Acesso em 15 de fev. 2020.

LEI No 10.778, DE 24 DE NOVEMBRO DE 2003. Estabelece a notificação compulsória, no território nacional, do caso de violência contra a mulher que for atendida em serviços de saúde públicos ou privados. Diário Oficial da União, Brasília, DF, 24 de nov de 2003. Disponível em: <http://www. planalto.gov.br/ccivil_03/LEIS/2003/L10.778.htm>. Acesso em 15 de fev. 2020.

LEI No 10.836, DE 9 DE JANEIRO DE 2004. Cria o Programa Bolsa Família e dá outras providências. Diário Oficial da União, Brasília, DF, 9 de jan de 2004. Disponível em: <http://www. planalto.gov.br/ccivil_03/_Ato2004-2006/2004/Lei/L10.836.htm>. Acesso em 15 de fev. 2020.

. LEI N 11.664, DE 29 DE ABRIL DE 2008. Dispõe sobre a efetivação de ações de saúde que assegurem a prevenção, a detecção, o tratamento e o seguimento dos cânceres do colo uterino e de mama, no âmbito do Sistema Único de Saúde - SUS. Diário Oficial da União, Brasília, DF, 29 de abril de 2008. Disponível em: <http://www.planalto.gov.br/ccivil_03/_ato2007-2010/2008/lei/ 111664.htm>. Acesso em 16 de fev. 2020.

LEI No 11.804, DE 5 DE NOVEMBRO DE 2008. Disciplina o direito a alimentos gravídicos e a forma como ele será exercido e dá outras providências. Diário Oficial da União, Brasília, DF, 5 de nov de 2008. Disponível em: <http://www.planalto.gov.br/ccivil_03/_ato2007-2010/2008/lei/ 111804.htm>. Acesso em 16 de fev. 2020.

DECRETO No 1.565, DE 21 DE JULHO DE 1995. Regulamenta a Lei $n^{\circ} 8.829$, de 22 de dezembro de 1993, que cria, no Serviço Exterior, as Carreiras de Oficial de Chancelaria e de Assistente de Chancelaria. Diário Oficial da União, Brasília, DF, 21 de jul de 1995. Disponível em: <http:// www.planalto.gov.br/ccivil_03/decreto/1995/D1565.htm>. Acesso em 16 de fev. 2020.

DECRETO No 4.675, DE 16 DE ABRIL DE 2003. Regulamenta o Programa Nacional de Acesso à Alimentação - "Cartão Alimentação", criado pela Medida Provisória no 108, de 27 de fevereiro de 2003. Diário Oficial da União, Brasília, DF, 16 de abril de 2003. Disponível em: <http:// www.planalto.gov.br/ccivil_03/decreto/2003/d4675.htm>. Acesso em 16 de fev. 2020.

LEI No 10.745, DE 9 DE OUTUBRO DE 2003. Institui o ano de 2004 como o "Ano da Mulher". Diário Oficial da União, Brasília, DF, 9 de out de 2003. Disponível em: <http://www. planalto.gov.br/ccivil_03/Leis/2003/L10.745.htm>. Acesso em 16 de fev. 2020.

LEI No 12.227, DE 12 DE ABRIL DE 2010. Cria o Relatório Anual Socioeconômico da Mulher. Diário Oficial da União, Brasília, DF, 12 de abril de 2010. Disponível em: <http://www. planalto.gov.br/ccivil_03/_Ato2007-2010/2010/Lei/L12227.htm>. Acesso em 16 de fev. 2020.

LEI No 12.288, DE 20 DE JULHO DE 2010. Institui o Estatuto da Igualdade Racial; altera as Leis nos 7.716, de 5 de janeiro de 1989, 9.029, de 13 de abril de 1995, 7.347, de 24 de julho de 1985, e 10.778, de 24 de novembro de 2003. Diário Oficial da União, Brasília, DF, 20 de jul de 2010. Disponível em: <http://www.planalto.gov.br/ccivil_03/_Ato2007-2010/2010/Lei/L12288.htm>. Acesso em 16 de fev. 2020.

MINISTÉRIO DA SAÚDE. 2004 Ano da Mulher. Brasília: Editora MS, 2004. Disponível em: <https://bvsms.saude.gov.br/bvs/publicacoes/2004_anodamulher.pdf>. Acesso em 25 de fev. 2020.

BRASIL, Patricia Cristina; MASSMANN, Débora Raquel Hettwer. A mulher, o direito e os fatos jurídicos. Interfaces Científicas: Humanas e Sociais, Aracaju, v. 6, n. 2, p. 137-150, out. 2017. 
BRUSCHINI, Cristina; LOMBARDI, Maria Rosa. Médicas, arquitetas, advogadas e engenheiras: mulheres em carreiras, profissionais de prestígio. Revista Estudos Feministas. Florianópolis: CFH/ UFSC/Rio: IFCS/UFRJ, n. 1 e 2, 1999.

COMPARATO, Fábio Konder. A afirmação histórica dos direitos humanos. São Paulo: Saraiva, 2015.

COSTA, Fabiana Alves da. Mulher, trabalho e família: os impactos do trabalho na subjetividade da mulher e em suas relações familiares. Pretextos - Revista da Graduação em Psicologia da PUC Minas v. 3, n. 6, p. 434-452, jul./dez. 2018.

FOUCAULT, Michel. História da Sexualidade. Rio de Janeiro: Edições Graal, 1999.

Microfísica do Poder. Rio de Janeiro: Graal, 1984.

FRANCO, M.L.P.B. O que é análise de conteúdo. São Paulo: PUC; 1986.

FRIEDAN, Betty. Mística Feminina. Petrópolis, Rj: Editora Vozes Limitadas, 1971.

GARCIA, Emerson. Proteção e Inserção da Mulher no Estado de Direito: a lei maria da penha: A Lei Maria da Penha. EMERJ, Rio de Janeiro, v. 12, n. 46, p. 182-2007, 2009.

GIL, Antonio Carlos. Como Elaborar Projetos de Pesquisa. São Paulo: Editora Atlas, 2002.

IBGE. Conheça o Brasil - População: Quantidade de Homens e Mulheres. Disponível em: Educa | Jovens - IBGE: <https://educa.ibge.gov.br/jovens/conheca-o-brasil/populacao/18320-quantidadede-homens-e-mulheres.html>. Acesso em 05 de mar. 2019

Estatísticas de Gênero. Disponível em: <https://www.ibge.gov.br/apps/snig/ $\mathrm{v} 1 /$ ?loc $=0 \&$ cat $=-15,-16,-17,-18,128 \&$ ind $=4704>$. Acesso em 19 de abril de 2020.

Indicadores Sociais das Mulheres no Brasil (2018). Disponível em: Educa | Jovens - IBGE

$<$ https://educa.ibge.gov.br/jovens/materias-especiais/materias-especiais/20453-estatisticas-degenero-indicadores-sociais-das-mulheres-no-brasil.html>. Acesso em 05 de mar. 2019.

MARQUES, Siomara Aparecida. Mulheres na carreira jurídica: subversão à concepção universal de sujeito moderno/sujeito de direito. 2004. 207 f. Tese (Doutorado) - Curso de Sociologia Política, Centro de Filosofia e Ciências Humanas, Universidade Federal de Santa Catarina, Florianópolis, 2004.

MINAYO, Maria Cecília de Souza. Análise qualitativa: teoria, passos e fidedignidade. Ciênc. saúde coletiva [online]. 2012, vol.17, n.3, pp.621-626.

OAB. Comissão Nacional da Mulher Advogada: Legislação. Disponível em: <https://www1.oab. org.br/cnma/Legislacao>. Acesso em: 20 de jan de 2020.

PISCITELLI, A. Interseccionalidades, categorias de articulação e experiências de migrantes brasileiras.

Sociedade e Cultura, v. 11, n. 2, 18 dez. 2008.

POPPER, Karl R. A lógica da Pesquisa Científica. São Paulo: Cultrix, 2013.

PRIORE, Mary del. História das Mulheres no Brasil. São Paulo: Contexto, 2004.

REALE, Miguel. Lições preliminares de direito. São Paulo: Saraiva, 2002.

ROCHA-COUTINHO, Maria Lucia. Tecendo por trás dos panos: A mulher brasileira nas relações familiares. Rio de Janeiro: Rocco, 1994.

SILVA, José Afonso da. Curso de direito constitucional positivo. São Paulo: Malheiros Editores, 2009.

SPINDOLA, Thelma; SANTOS, Rosangela da Silva. Mulher e trabalho - a história de vida de mães trabalhadoras de enfermagem. Rev. Latino-am. Enfermagem, Ribeirão Preto, v. 11, n. 5, p.593-600, out. 2003.

WEBER, Max. Economia e Sociedade: fundamentos da sociologia compreensiva volume I. Brasília: UNB, 2000.

Ensaios de Sociologia. Rio de Janeiro: Livros Técnicos e Científicos Editora, 1982.

Data submissão: 26/05/2020

Data aprovação:17/07/2020 